\title{
ENHANCED URBAN LANDCOVER CLASSIFICATION FOR OPERATIONAL CHANGE DETECTION STUDY USING VERY HIGH RESOLUTION REMOTE SENSING DATA
}

\author{
S. D. Jawak ${ }^{\mathrm{a}, *}$, S. N. Panditrao ${ }^{\mathrm{b}}$, A. J. Luis ${ }^{\mathrm{a}}$

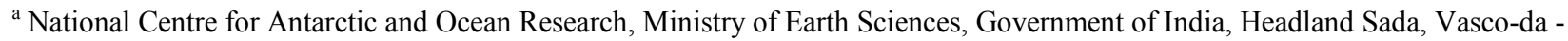 \\ Gama, Goa 403804, India - shridhar.jawak@gmail.com, alvluis1@gmail.com \\ ${ }^{\mathrm{b}}$ Indian National Centre for Ocean Information Services, Ministry of Earth Sciences, Government of India, Ocean Valley, Pragathi \\ Nagar, Nizampet, Hyderabad 500090, India - satej.panditrao@gmail.com
}

KEY WORDS: WorldView-2, QuickBird, Support Vector Machine, Change Detection

\begin{abstract}
:
This study presents an operational case of advancements in urban land cover classification and change detection by using very high resolution spatial and multispectral information from 4-band QuickBird (QB) and 8-band WorldView-2 (WV-2) image sequence. Our study accentuates quantitative, pixel based, image difference approach for operational change detection using very high resolution pansharpened QB and WV-2 images captured over San Francisco city, California, USA (37 44" 30N', $122^{\circ} 31^{\prime \prime} 30^{\prime}$ W and 37 41" $\left.30^{\prime} \mathrm{N}, 122^{\circ} 20^{\prime \prime} 30^{\prime} \mathrm{W}\right)$. In addition to standard QB image, we compiled three multiband images from eight pansharpened WV-2 bands: (1) multiband image from four traditional spectral bands, i.e., Blue, Green, Red and near-infrared 1 (NIR1) (henceforth referred as "QB equivalent WV-2"), (2) multiband image from four new spectral bands, i.e., Coastal, Yellow, Red Edge and NIR2 (henceforth referred as "new band WV-2"), and (3) multiband image consisting of four traditional and four new bands (henceforth referred as "standard WV-2"). All the four multiband images were classified using support vector machine (SVM) classifier into four most abundant land cover classes, viz, hard surface, vegetation, water and shadow. The assessment of classification accuracy was performed using random selection of 356 test points. Land cover classifications on "standard QB" image (kappa coeffiecient, $\kappa=$ 0.93), "QB equivalent WV-2" image ( $\kappa=0.97)$, and "new band WV-2" image $(\kappa=0.97)$ yielded overall accuracies of $96.31 \%$, $98.03 \%$ and $98.31 \%$, respectively, while "standard WV-2" image $(\kappa=0.99)$ yielded an improved overall accuracy of $99.18 \%$. It is concluded that the addition of four new spectral bands to the existing four traditional bands improved the discrimination of land cover targets, due to increase in the spectral characteristics of WV-2 satellite. Consequently, to test the validity of improvement in classification process for implementation in operational change detection application, comparative assessment of transition of various landcover classes in three WV-2 images with respect to "standard QB" image was carried out using image difference method. As far as waterbody class is concerned, there was no significant transition observed in all the three WorldView-2 Images, whereas, hard surface class showed lowest transition in "standard WV-2" image and highest in case of "new band WV-2". The most significant transition was occurred in vegetation class in all of the three images, showing positive change (increase) in standard WV-2 image (0.31 Sq. Km) and negative change (decrease) in other two images (-0.12 Sq. Km for "QB equivalent WV-2" image and -31.15 Sq. $\mathrm{Km}$ in "new band WV-2" image) with considerable amount. Similar case was observed with the shadow class, but the difference is, transition from shadow to other classes was negative in all the three WV-2 images which can be attributed to the fact that, "standard QB" image had more shadow area (based on acquisition time and sun position) than WV-2, that means all the band combinations of WV-2 succeeded in extracting the features hidden below the shadow in "standard QB" image. These trends indicate that the overall bandwise transition in landcover classes in case of "standard WV-2" is more precise than other two images. We note that "QB equivalent WV-2" image had narrower band widths than those of "standard QB" image but the observed vegetation change is not prominent as in case of other two images, but at the same time, transition in hard surface and waterbody was discerned more efficiently than "new band WV-2" image. The addition of new bands in WV-2 enabled more effective vegetation analysis, so the vegetation transition results shown by "new band WV-2" image were at par with the "standard WV-2" image, showing the importance of these newly added bands in the WV-2 imagery, with comparatively lower transitions in other classes. In a nutshell, it can be claimed that incorporation of new bands along with even narrower Red, Green, Blue and Near Infrared-1 bands in WV-2 image holds remarkable importance which leads to enhancement in the potential of WV-2 imagery in change detection and other feature extraction studies.
\end{abstract}

\section{INTROCUCTION}

Urban land cover mapping using geospatial information technology (GIT) has been widely explored and exploited, especially with the recent advances and emergence of very high resolution (VHR) images and advanced classification techniques (Blaschke, 2010; Jawak and Luis, 2013a; Jawak and Luis, 2013b; Jawak and Luis, 2012; Jawak and Luis, 2014a; Jawak and Luis, 2014b). Temporal change detection in land cover using remote sensing (RS) is a topic of rigorous research since last few years. Timely updating of land use and land cover (LULC) datasets is necessary as they constitute the basic source of many studies (DeFries, 2013). RS has now become one of the major sources of data for mapping and monitoring LULC dynamics over time (Xian et al., 2009; Hansen and Loveland, 2012). A large number of change detection techniques and algorithms have been developed since last few years, but still change detection is an active and miscellaneous research topic (Singh, 1989; Lu et al. 2004; Bhagat, 2012; Hussain et al., 2013) and a lot of new techniques are being developed for

\footnotetext{
* Corresponding author.
} 
effective feature extraction purposes by incorporating various RS imagery and ancillary data (Ardila Lopez et al., 2012; Chen et al., 2013; Hussain et al., 2013; Kim et al., 2013; Jawak and Luis, 2011). In case of temporal change detection using principal component (PC) analysis, both the surface proportion and the magnitude of the changed area in an image determine which principal component images will contain change information. It is nothing but the comparative amount of variance between the changed area and the unchanged region in an image that determines which specific PCs contain change information (Parra et al., 1996). According to Jensen (1997), post-classification comparison of changes is the most widely used method for quantitative analysis. It requires a complete classification of the individual dates of remotely sensed data, whereupon the operator produces a matrix of change that identifies 'from-to' land cover change classes. But, the drawback with this method is errors in the individual data classification map will also be noticeable in the final change detection (Metternicht, 1999). Different LULC types have different spectral signatures, and these signatures change as per the changes in LULC types, so by comparing the changes in the spectral signatures of two points in time using proper algorithms result in change detection ( $\mathrm{Lu}$ et al. 2004b). Various strategies are being defined that are able to exploit all the available geometrical information for the precise analysis of multitemporal acquisitions. A whole lot of factors such as, atmospheric correction, image registration, change detection methods, topography, characteristics of remote sensing data sets etc. should be taken into consideration for precise change detection results (Lu et al., 2004). Hence, change detection is a complex process which demands insightful consideration of above mentioned parameters. After selecting the study area and RS imagery, selection of different landcover classes/variables becomes very crucial. As of now, study area driven approaches for change detection are still not developed up to the mark due to the scarcity of guidelines for designing optimal change detection procedure which takes into account different characteristics of study areas along with different kinds of RS imagery (Lu et al., 2004; Hussain et al., 2013). Image preprocessing is also important in change detection studies, like pansharpening, radiometric/atmospheric correction, geometric rectification/registration etc. in addition to selection of variables like pixel based or sub-pixel based or object based as per the requirement ( $\mathrm{Lu}$ et al., 2014). The WorldView-2 (WV-2) satellite is the first high spatial resolution space-borne sensor with eight spectral bands ranging from blue to the near infrared parts of the electromagnetic spectrum (DigitalGlobe, 2010). The additional Coastal Blue (400-450 nm), Yellow (585-625 $\mathrm{nm})$, Red-Edge $(705-745 \mathrm{~nm})$ and NearIR-2 (860-1,040 nm) bands can provide an increase of up to $30 \%$ in the classification accuracy, if compared to analyses performed with only the four multispectral bands also available in sensors like the GeoEye-1, Ikonos or the QuickBird (QB) (DigitalGlobe, 2010). In this context, the aim of this study is to investigate, whether the WV2 sensor has indeed a higher potential than the QB sensor for change detection studies. This paper offers a systematic procedure for landcover change detection using very high resolution satellite images.

\section{STUDY AREA AND DATA}

In order to study change detection using very high resolution satellite data, we selected the part of San Francisco city, California, United States of America ( $37^{\circ} 44^{\prime \prime} 30 \mathrm{~N}^{\prime}, 122^{\circ} 31^{\prime \prime}$ $30^{\prime} \mathrm{W}$ and $37^{\circ} 41^{\prime \prime} 30^{\prime} \mathrm{N}, 122^{\circ} 20^{\prime \prime} 30^{\prime} \mathrm{W}$ ), as a test scene. It is a highly dense urban area which consists of large number of tall buildings as well as other urban features like stadiums, roads, bridge and vegetation/trees. WorldView-2 (WV-2) image of the study area captured on $9^{\text {th }}$ October, 2011 is shown in Figure 1. We used two VHR datasets for temporal change detection study (Table 1 and Table 2).

\begin{tabular}{lll}
\hline Sensor name & Band name & Range (nm) \\
\hline WorldView-2 & Band 1 - NIR1 & $770-895$ \\
& Band 2 - Red & $630-690$ \\
& Band 3 - Green & $510-580$ \\
& Band 4 - Blue & $450-510$ \\
& Band 5 - RedEdge & $702-741$ \\
& Band 6 - Yellow & $586-624$ \\
& Band 7 - Coastal & $401-450$ \\
& Band 8 - NIR2 & $458-450$ \\
& Panchromatic & $450-800$ \\
& Band 1 - Blue & $450-520$ \\
& Band 2 - Green & $520-600$ \\
& Band 3 - Red & $630-690$ \\
& Band 4 - NIR & $760-900$ \\
& Panchromatic & $450-900$ \\
\hline
\end{tabular}

Table 1. Spectral specifications of VHR sensors

\begin{tabular}{lll}
\hline Sensor & Resolution & Acquisition date \\
\hline WorldView-2 PAN & 0.5 Meters & $9^{\text {th }}$ October 2011 \\
WorldView-2 MS & 2.0 Meters & $9^{\text {th }}$ October 2011 \\
Quickbird PAN & 0.6 Meters & $11^{\text {th }}$ November 2007 \\
Quickbird MS & 2.5 meters & $11^{\text {th }}$ November 2007 \\
\hline
\end{tabular}

Table 2. VHR datasets used in present study

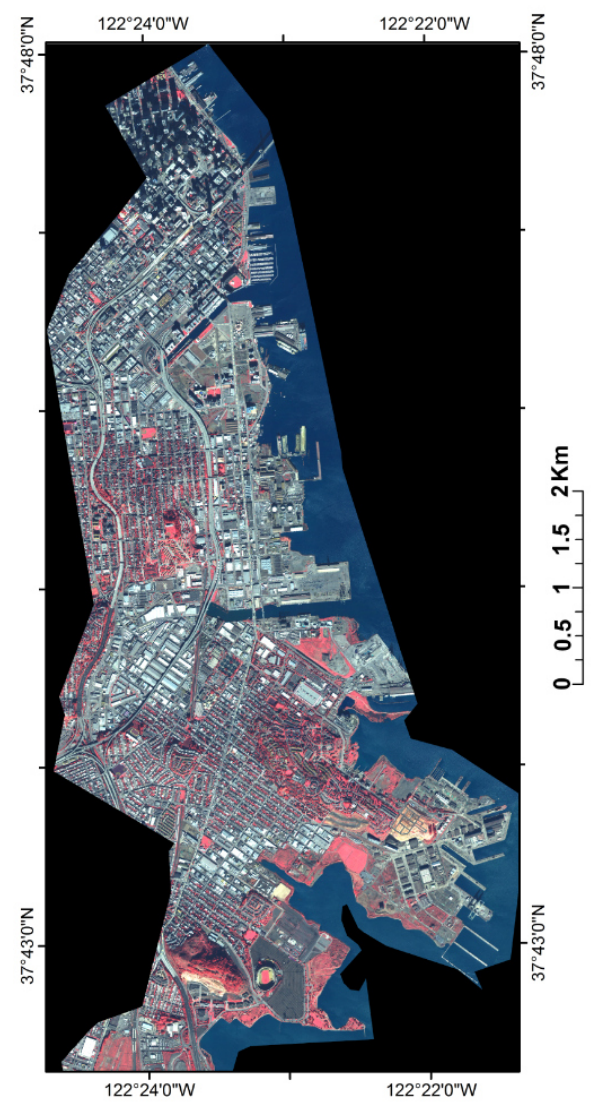

Figure 1. WorldView-2 image of the study area 


\section{METHODOLOGY}

Three steps were followed in this study for systematic image processing (Figure 2). 1) Data pre-processing 2) PANsharpening and multiband image generation and 3) Supervised Classification using SVM algorithm and subsequent accuracy assessment. Data pre-processing involved two sub-steps, a) Dark pixel/object subtraction and b) Data calibration. The dark pixel subtraction was meant for reducing the path radiance from each band (Jawak and Luis, 2013c). The dark object is nothing but the least digital number (DN) value for more than 1000 pixels over the whole image (Teillet and Fedosejevs, 1995; Jawak et al., 2013). For data calibration, two step approach was followed, (adapted from DigitalGlobe, 2010): i) Conversion of the raw digital number values to at-sensor spectral radiance factors and ii) Conversion from spectral radiance to Top-of Atmosphere Reflectance (TOA). Gram-Schmidt PANsharpening algorithm was employed for PAN-sharpening of three WV-2 images and one QuickBird (QB) image (Laben et al., 2000; Jawak and Luis, 2013d). PAN-sharpened WV-2 image was downsampled to $0.6 \mathrm{~m}$ resolution to match the resolution of QB PAN-sharpened image. For assessing the comparative performance of new/add-on WV-2 bands, three multiband images were generated from eight PAN-sharpened bands. The first image comprised of traditional four VNIR bands of WV-2, i.e., Blue, Green, Red and NIR1. This image was equivalent to the $\mathrm{QB}$ image generated using spectral bands with narrow band-widths.
The second image was compiled by using four new/add-on bands of WV-2, i.e., Coastal, Yellow, Red Edge and NIR2. The third image was standard WV-2 image with all the eight bands (traditional + new bands). All the four multiband images were classified using support vector machine (SVM) classifier into four most abundant land cover classes, viz, hard surface, vegetation, water and shadow (Mountrakis et al., 2010). The "salt and pepper" effect is a common by-product of pixel-based classifications and is particularly conspicuous in VHR images, in which image pixels are smaller than the elements in the scene. This procedure results into noisy appearance of land cover maps. In spatially complex environments such as urban regions, this type of spectral heterogeneity of some surface types intensifies the salt-and-pepper problem. Thus, post classification processes were applied over classified images to eliminate isolated pixels, and to generate an apparently less noisy classified maps. Accuracy of classification was evaluated by using traditional confusion matrix based measures. Land cover classifications on "QB equivalent WV-2" image $(\kappa=$ $0.97)$, and "new band WV-2" image $(\kappa=0.97)$ yielded overall accuracies of $96.31 \%, 98.03 \%$ and $98.31 \%$, respectively, while "standard WV-2" image $(\kappa=0.99)$ yielded an improved overall accuracy of $99.18 \%$. Image difference method was used for change detection for comparative assessment of transition of land cover classes in three WV2 images with respect to "standard QB" image. Transition of each class into another classes in all the three images was determined and quantitative assessment was done.

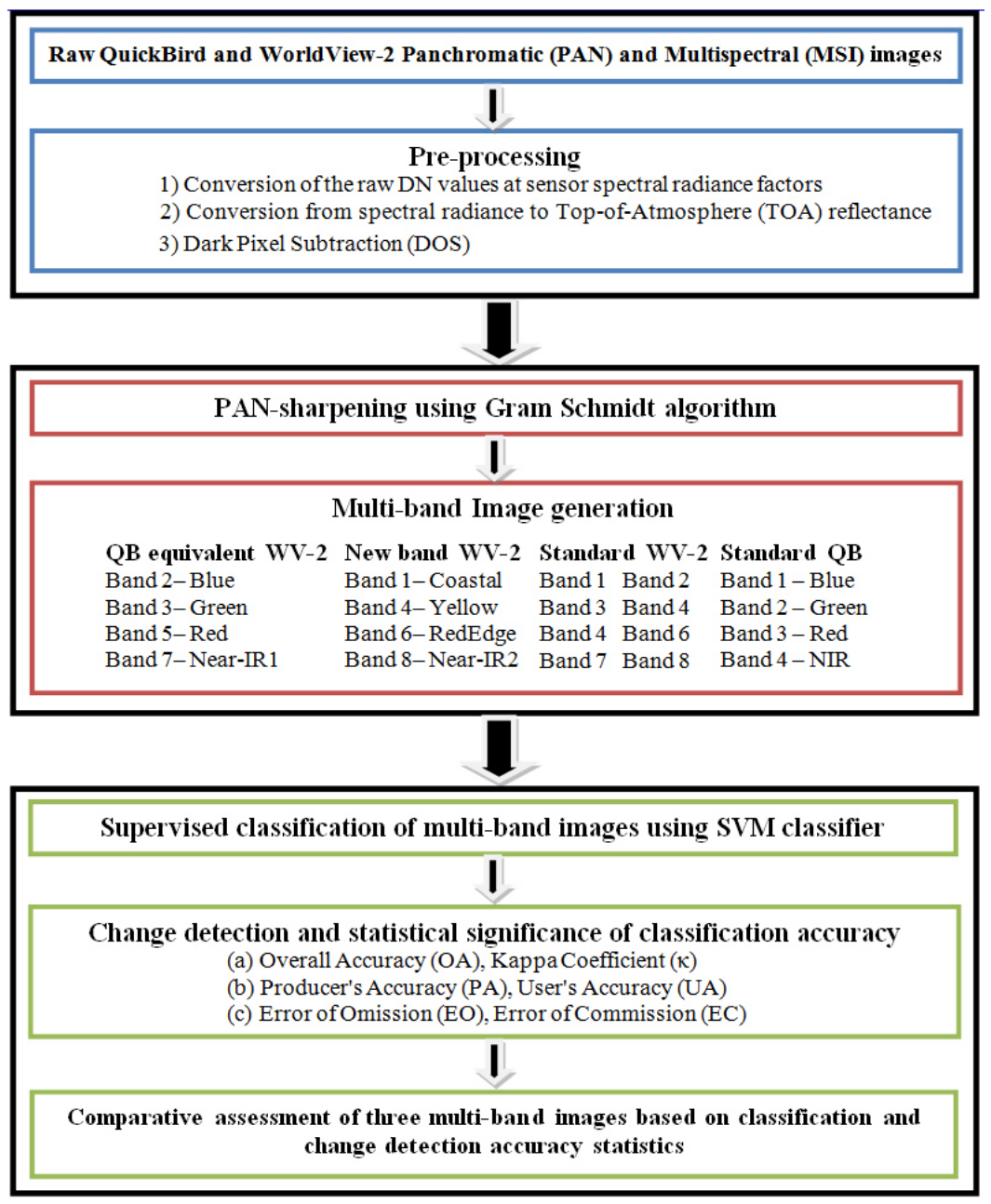

Figure 2. Methodology flowchart implemented in the present study 


\section{RESULTS}

Figure 3 and 4 shows the transitions between all the land cover classes defined in the presnet study. As far as waterbody class is concerned, there was no significant transition observed in all the three WorldView-2 images, whereas, hard surface class showed the highest transition in "standard WV-2" image and lowest in case of "new band WV-2". It is important to note that the accuracy of waterbody classification is highest in all the three multiband images, while 8-band image performed very well in extracting shadows. Our experiment achieved $0.28 \%$ improvement in accuracy with the usage of 4 new bands as compared to traditional bands. Landcover area statistics for all the classified images is depicted in Table 2
Furthermore, the use of 8-band image produced $99.18 \%$ accuracy $(1.15 \%$ more than traditional four band image and $0.83 \%$ more than four new band image), equivalent to an improvement of 0.2 in kappa value. It exhibits that, the use of all 8 bands ( 4 traditional spectral bands and 4 new spectral bands) improved the accuracy at highest level, as compared to four traditional multiband and four new multiband image. The most significant transition was occurred in vegetation class in all of the three images, showing positive change (increase) in standard WV-2 image $(0.31 \mathrm{Sq} . \mathrm{Km})$ and negative change (decrease) in other two images (-0.12 Sq. Km) for "QB equivalent WV-2" image and $-31.15 \mathrm{Sq}$. Km in "new band WV2 " image) with considerable amount.

\section{Landcover Transition Map of San Francisco ( Year 2007-2011)}

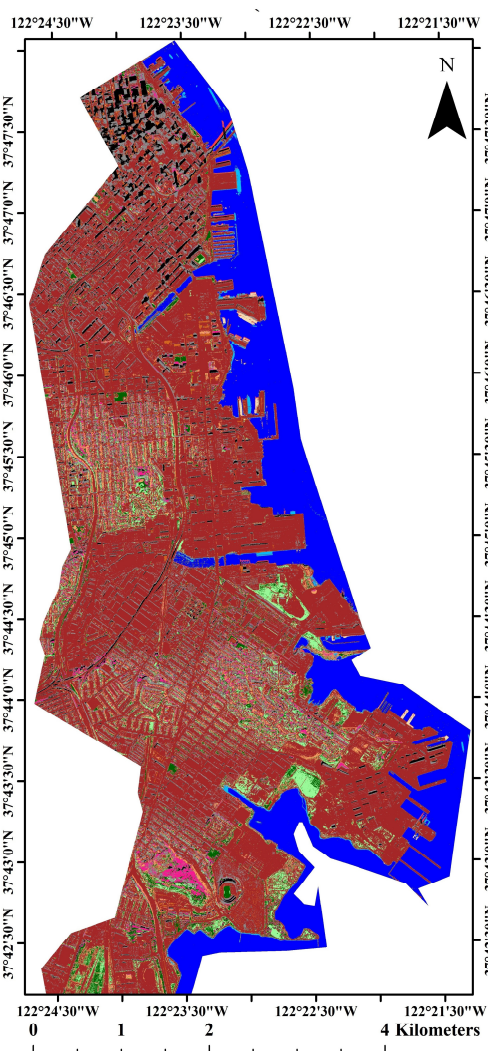

Satellite: Standard Quickbird (2007) - 4 Bands, Standard WorldView-2 (2011) - 8 Bands

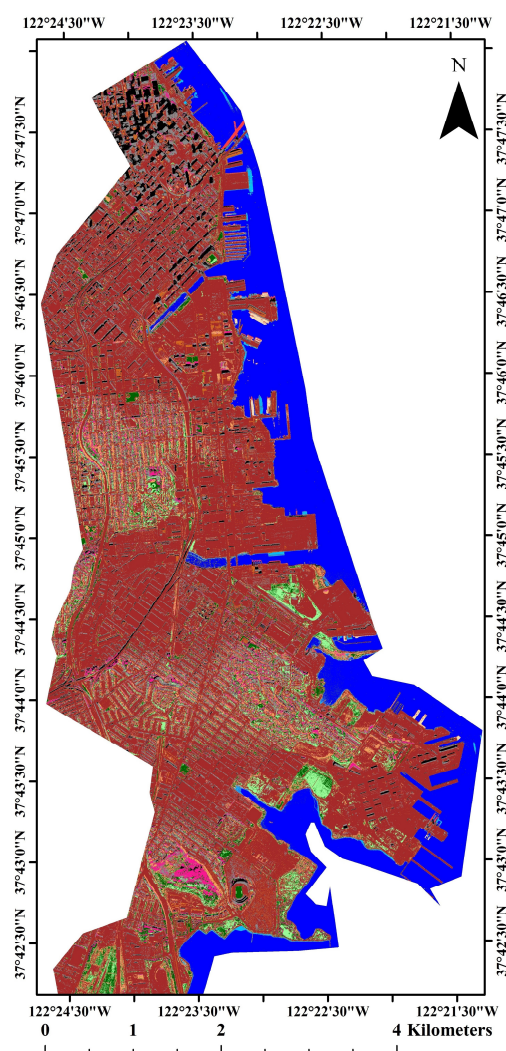

Satellite: Standard Quickbird (2007) - 4 Bands, Quickbird Equivalent WorldView-2 (2011) 4 Existing Bands

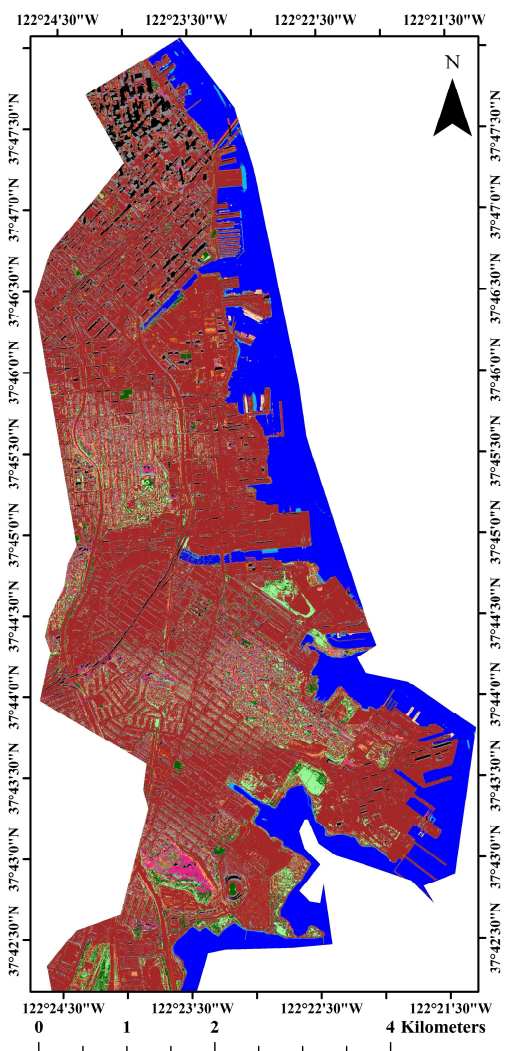

Satellite: Standard Quickbird (2007) - 4 Bands, New Band WorldView-2 (2011) - 4 New Bands
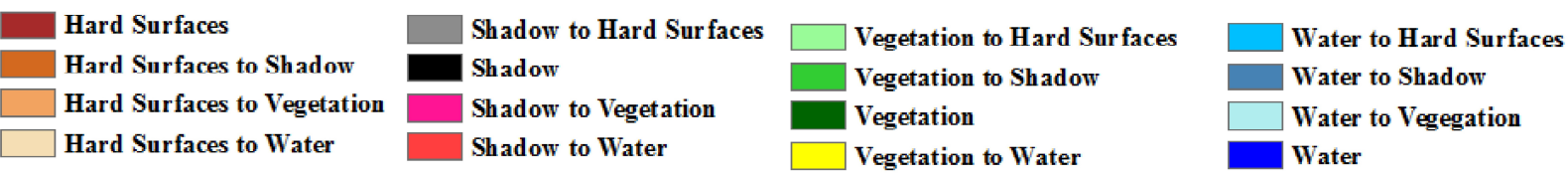

Figure 3. Class transition map for various band combinations of WV-2 and QB images

\begin{tabular}{lllll}
\hline Satellite Image & Hard Surfaces & Water body & Vegetation & Shadow \\
\hline Standard WV-2 (2011) & 17.88 & 5.59 & 4.79 & 1.75 \\
Standard QB (2007) & 16.70 & 5.77 & 2.17 & 5.27 \\
QB Equivalent WV-2 (2011) & 18.61 & 5.64 & 3.50 & 2.26 \\
New Band WV-2 (2011) & 19.92 & 5.69 & 2.90 & 1.74 \\
\hline
\end{tabular}

Table 2. Landcover class area values (sq.km) for all the four classified images. 

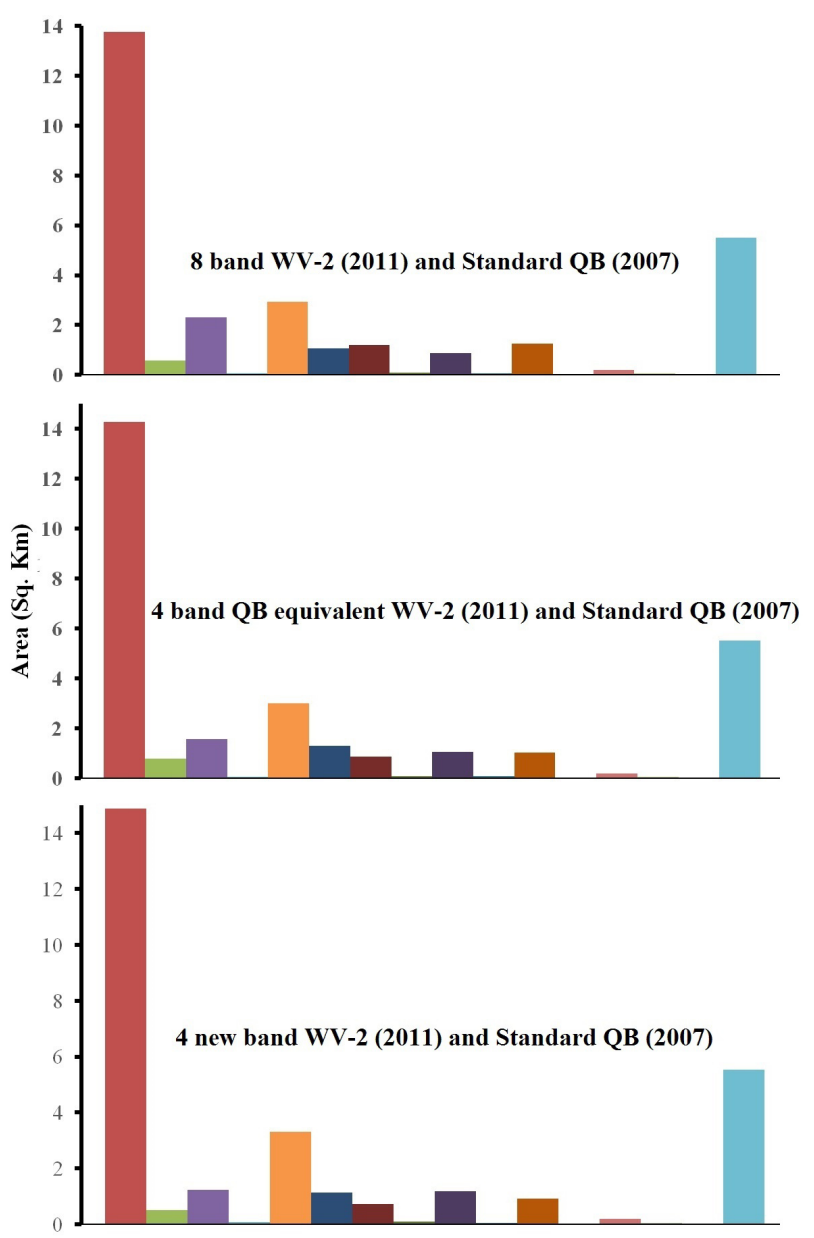

Transition Class

- Hard Surfaces (Unchanged) $\quad$ Hard Surfaces - Shadow

- Shadow - Hard Surfaces $\quad$ Shadow (Unchanged)

- Vegetation - Hard Surfaces $\quad$ Vegetation -Shadow

Water - Hard Surfaces $\quad$ Water - Shadow

-Hard Surfaces -Vegetation $\quad$ Hard Surfaces - Water

- Shadow -Vegetation

- Vegetation (Unchanged)

- Shadow - Water

Vegetation - Water

- Water - Vegegation

water (Unchanged)

Figure 4. Change detection maps showing landcover transition from 2007 to 2011

Similar case was observed with the shadow class, but the difference is, transition from shadow to other classes was negative in all the three WV-2 images which can be attributed to the fact that, "standard QB" image had more land cover area hidden under shadow (based on acquisition time and sun position) than $\mathrm{WV}-2$, that means all the band combinations of WV-2 succeeded in extracting the features hidden below the shadow in "standard QB" image. Furthermore, the spatial resolution difference between QB and WV2 was an important factor in the present study, especially in shadow and vegetation boundary pixels, so the results could have been improved to some extent if images of the same resolutions were used. All the pre-processing steps turned out to be useful and thresholds used in them were optimum. Especially, Gram-Schmidt process for PAN sharpening yielded very precise results in all the images. So, it is one of the best methods for these kind of studies along with dark pixel subtraction. The overall transition in all the classes was more precise in "standard WV2" than other two images and vegetation transition in "new band WV2" was approximately same as that in "standard WV2", which is an indicator of the enhanced efficiency of WV2 image in feature extraction/delineation. QB equivalent WV2 image had narrower bands than those of standard QB image, so the transition of hard surface and waterbody was observed more effectively than "new band WV2" image. So, it can be concluded that "Standard WV2" is the best among all the images and holds superlative potential for feature extraction studies.

\section{DISCUSSION}

In the study, the spectral characteristics of land cover classes were analysed by employing combination of image processing methods on WV-2 imagery. The use of recent GS-sharpening algorithm coupled with SVM classification method provided an effective platform to support urban land-cover classification. The presence of eight bands in satellite mission like WV-2 offer an opportunity to address and solve some of the traditional land cover classification problems related to the low spatial and/or spectral resolution, such as lack of details for certain features or the inability of the conventional classifiers to detect some land cover types because of missing efficient spectrum information and analysis techniques. Nevertheless, the visual image interpretation can be very time-consuming while automatic classification methods devised in the last few years still face some limitations. These limitations are no longer related to the coarse spatial resolution of the sensors because the imagery from several space-borne sensors with sub-meter spatial resolution is available for the last ten years. Obtaining better results is most frequently hampered by the fact that these sensors provide images with only four traditional spectral bands which makes the distinction of land cover classes of similar coloration a difficult task. The newly introduced unique WV-2 channels enable access to spectral regions where distinguishable differences exist between different target classes within the scene, which may be overlooked by traditional MS systems. In the present study, new "add on" bands were tested for change detection studies and are found to be useful to ensure a high precision in spectral analysis for land cover mapping and change detection. The present research can also be extended for monitoring applications such as land use planning strategies, disaster relief, exploration, defence and intelligence, and visualization and simulation environments.

We note that the parameters used for SVM classification were kept constant for the classification of three multiband images, to ensure the unbiased accuracy analysis. Our research is based on the strength of traditional and new spectral bands. The accuracy statistics suggest that the 8-band image performed much better than the 4-band traditional and new multiband image, improving the mapping accuracy and hence the subsequent change detection. Although our method successfully improved mapping accuracy, there are two limitations to the method. First, 8-band data is a new innovation in high-resolution satellite RS technology and cannot be directly compared with hyperspectral data. As a result, it was necessary to design classification strategy on a trial-and-error. Second, the experiment was limited to a single WV-2 image sequence, which does not represent all the land cover classes.

\section{CONCLUSION}

The image products available from new satellite sensors with very high spatial-spectral resolution provide a potential for applications in urban land-mapping applications. The objective of this study was to develop a methodology using eight spectral 
bands and advanced classification technique to map land cover with WV-2 images more effectively than the traditional multiband image to improve the change detection application. Our study used the SVM classifier and WV-2 sensor imagery, two technologies which are new and still less explored in land cover mapping applications. The new WV-2 bands permit recognition and extraction of the various urban land cover features, because these bands are located on important regions of the electromagnetic spectrum. The study led us to the following two conclusions. (1) In general, the combination of traditional and new spectral bands yielded the highest accuracy for classification. (2) The traditional and new spectral bands contributed evenly for the success of classification. (3) The addition of the four new bands facilitated proper discrimination of water, shadow, hard surfaces, and vegetation cover. (4) The variation in the performance of three multiband images in classification process can be attributed to the individual bands used for their generation. (5) The eight-band imagery and advanced classifier can greatly improve the final output of land cover mapping, when compared with the traditional mapping using four band acquisition.(6) Accuracy of change detection study is dependent on the type of spectral bands utilized in the classification process.

The inclusion of four new bands in WV2 image turned out to be very prolific in change detection process. The results could have been improved if the images were of the same resolution. Standard WV2 image produced the most precise results in change detection which shows its efficiency in feature extraction process. In a nutshell, it can be claimed that incorporation of new bands along with even narrower Red, Green, Blue and Near Infrared-1 bands in WV-2 image holds remarkable importance which leads to enhancement in the potential of WV-2 imagery in change detection and other feature extraction studies.

The present work reinforces the view that the 8-band WV-2 satellite data provides a decisive tool for image classification for land cover mapping and consequent change detection studies. Overall, the research indicates that WV-2 can significantly improve the visual interpretation and the change detection is a powerful tool in the monitoring of urban regions. It is concluded that the addition of four new spectral bands to the existing four traditional bands improved the discrimination of land cover targets, due to an increase in the spectral characteristic of WV-2 sensor.

\section{ACKNOWLEDGEMENT}

We are indebted to the organizers of the IEEE GRSS Data Fusion Contest (2012), who provided the data to our research team free of cost. We also acknowledge Dr. Rajan, Director, NCAOR, Dr. R. Ravindra, ex-Director, NCAOR, and Prof. Anjana Vyas, CEPT University for their encouragement and motivation for this research. This is NCAOR contribution no. $38 / 2014$

\section{REFERENCES}

Ardila Lopez, J.P., et al., 2012. Multitemporal change detection of urban trees using localized region-based active contours in VHR images. Remote Sensing of Environment, 124, pp. 413426.
Bhagat, V.S., 2012. Use of remote sensing techniques for robust digital change detection of land: a review. Recent Patents on Space Technology, 2, 123-144.

Blaschke, T., 2010. Object based image analysis for remote sensing. ISPRS Journal of Photogrammetry and Remote Sensing, 65, pp. 2-16.

Chen, J., et al., 2013. A spectral gradient difference based approach for land cover change detection. ISPRS Journal of Photogrammetry and Remote Sensing, Vol. 85, pp. 1-12.

DeFries, R., 2013. Why forest monitoring matters for people and the planet. In: F. Achard and M.C.Hansen, eds. Global forest monitoring from earth observation. Boca Raton, FL: CRC Press/Taylor \& Francis Group, pp. 1-14.

DigitalGlobe ${ }^{\circledR}$. The Benefits of the 8 Spectral Bands of WorldView-2; 2010. Available online: http://www.digitalglobe.com/index.php/88/WorldView-2 (3 Jul. 2011).

Hansen, M.C. and Loveland, T.R., 2012. A review of large area monitoring of land cover change using Landsat data. Remote Sensing of Environment, 122, pp.66-74.

Hussain, M., et al., 2013. Change detection from remotely sensed images: from pixel-based to object-based approaches. ISPRS Journal of Photogrammetry and Remote Sensing, 80, pp. 91-106.

Jawak, S.D., Luis, A.J., 2013a. Improved land cover mapping using high resolution multi-angle 8-band WorldView-2 satellite remote sensing data. Journal of Applied Remote Sensing, 7(1), 073573 .

Jawak, S.D., Luis, A.J., 2013b. A spectral index ratio-based Antarctic land-cover mapping using hyperspatial 8-band WorldView-2 imagery. Polar Science, 7(1), pp. 18-38.

Jawak, S.D., Luis, A.J., 2013c. Very-high resolution remotely sensed satellite data for improved land cover extraction of Larsemann Hills, east Antarctica. Journal of Applied Remote Sensing, 7(1), 073460.

Jawak, S.D., Luis, A.J., 2013d. A comprehensive evaluation of PAN-sharpening algorithms coupled with resampling methods for image synthesis of very high resolution remotely sensed satellite data. Advances in Remote Sensing, 2(4), pp. 332-344.

Jawak, S.D., Luis, A.J., 2014a. A semiautomatic extraction of Antarctic lake features using WorldView-2 imagery. Photogrammetric Engineering \& Remote Sensing 80(10), pp. 33-46.

Jawak, S.D., Luis, A.J., 2014b. Spectral Bands of WorldView-2 Satellite Remote Sensing Data for Semiautomatic Land Cover Extraction in the Antarctic Environment, XXXIII SCAR and $6^{\text {th }}$ Open Science Conference, Auckland, New Zealand, pp. 911.

Jawak, S.D., Luis, A.J., Panditrao, S.N., Khopkar, P.S., and Jadhav, P.S., 2013. Advancement in landcover classification using very high resolution remotely sensed 8-band WorldView2 satellite data. International Journal of Earth Sciences and Engineering. 06(02), pp. 1742-1749. 
Jawak, S.D., Luis, A.J., 2012. WorldView-2 satellite remote sensing data for polar geospatial information mining of Larsemann Hills, East Antarctica. In: Proceedings of $11^{\text {th }}$ Pacific (Pan) Ocean Remote Sensing Conference (PORSEC), Id: PORSEC2012-24-00006, Kochi, Kerala, India.

Jawak, S.D., Luis, A.J., 2011. Applications of WorldView-2 satellite data for extraction of polar spatial information and DEM of Larsemann Hills, East Antarctica, International Conference on Fuzzy Systems and Neural Computing (FSNC 2011), Vol. 3, pp. 148-151.

Jensen, J., 1997. Principles of change detection using digital remote sensor data. In: Star, Estes, McGwire (Eds.), Integration of Geographic Information Systems and Remote Sensing. Cambridge Univ. Press, pp. 37-54.

Kim, D., et al., 2013. Statistical trend and change-point analysis of land-cover-change patterns in East Africa. International Journal of Remote Sensing, 34 (19), pp. 6636-6650.

Laben, C. A., Brower, B. V., 2000. Process for enhancing the spatial resolution of multispectral imagery using pansharpening. United States Patent No. 6011875.

Lu, D., et al., 2004. Change detection techniques. International Journal of Remote Sensing, 25 (12), pp. 2365-2407.

Lu, D., et al., 2014. Current situation and needs of change detection techniques. International Journal of Image and Data Fusion, 5(1), pp. 13-38, DOI:10.1080/19479832.2013.868372

Metternicht, G., 1999. Change detection assessment using fuzzy sets and remotely sensed data: an application of topographic map revision. ISPRS Journal of Photogrammetry \& Remote Sensing, 54, pp. 221-233.

Mountrakis, G., Im, J., Ogole, C., 2010. Support vector machines in remote sensing: A review. ISPRS Journal of Photogrammetry and Remote Sensing, 66 pp. 247-259.

Parra, G.A., Mouchot, M.C. and Roux, C., 1996. A multitemporal land-cover change analysis tool using change vector and principal components analysis. Proceedings of IGARSS'96 Symposium, 27-31 May, Lincoln, Nebraska, USA (Piscataway, NJ: IEEE), Vol. 1, pp. 1753-1755.

Singh, A., 1989. Digital change detection techniques using remotely sensed data. International Journal of Remote Sensing, 10, pp. 989-1003.

Teillet, P. M., Fedosejevs, G., Gauthier, D., D’Iorio,M. A., 1995. Initial Examination of Radar Imagery of Optical Radiometric calibration sites. Proceedings of the SPIE Conference on Earth Observing Systems IV, SPIE, Denver, Colorado, 3750, pp. 470-481

Xian, G., Homer, C., and Fry, J., 2009. Updating the 2001 National Land Cover Database land cover classification to 2006 by using Landsat imagery change detection methods. Remote Sensing of Environment, 113 (6), pp. 1133-1147. 